\title{
Multimorbidity daily life activities and socio-economic classification in the Central Portugal primary health care setting: an observational study
}

\author{
LUIZ MIGUEL SANTIAGO ${ }^{1-3, A-G}$, FILIPE PRAZERES4, 5, C-E , TÂNIA BOTO ${ }^{1, A, ~ C-F}$, \\ ORCID: 0000-0002-9343-2827 ORCID: 0000-0002-2849-5194 ORCID: 0000-0001-8273-8129 \\ KATIA MAURÍCIO1, D, E, INÊS ROSENDO1,2, 5, D-G, JOSÉ AUGUSTO SIMÕES 2, 4, 5, D-G

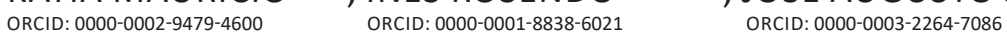 \\ ${ }^{1}$ Faculty of Medicine, University of Coimbra, Portugal \\ ${ }^{2}$ University Clinic of General and Family Medicine, Faculty of Medicine, University of Coimbra, Portugal \\ ${ }^{3}$ CEISUC - Centre for Health Studies and Investigation of the University of Coimbra, Portugal \\ ${ }^{4}$ Faculty of Health Sciences, University of Beira Interior, Covilhã, Portugal \\ ${ }^{5}$ CINTESIS - Centre for Research in Health Technologies and Service, Porto, Portugal
}

A - Study Design, B - Data Collection, C - Statistical Analysis, D - Data Interpretation, E - Manuscript Preparation, F - Literature Search, G - Funds Collection

Summary Background. Multimorbidity (MM) is associated with decreased quality of life, mainly due to decreased functional capacity and increased use of health care.

Objectives. Evaluate the prevalence of MM in older people of Central Portugal and understand the impact of MM on daily life activities (DLA) and how socio-economic level influences the prevalence of MM.

Material and methods. Observational study of data on age, sex, number of ICPC2 codes and Barthel (Bt) and Graffar (Gr) Indexes in clinical records of individuals aged between 65 to 99 years enrolled in the Health Centres of the Central Region of Portugal. The Bt was used to assess the dependence on DLA, and the Gr the socio-economic level.

Results. Population of 190,025 , mean age of $80.16 \pm 8.03$ years. MM prevalence of $80 \%$, out of which $52.9 \%$ were female, and the majority was aged between $76-85$ years (39.1\%). Average number of health problems: 8.7 problems for males and 9.5 for females. Bt and $\mathrm{Gr}$ Indexes we filled in $7.4 \%$ and $4.9 \%$ of the population. Older people without MM have higher dependency rates than those with MM (total dependence $7.4 \%$ vs $6.2 \%$ and severe dependence $20.1 \%$ vs $9.6 \%)$. MM in older people is mainly in the middle $(55.3 \%$ vs $27.5 \%)$ and low (31.8\% vs $19.6 \%)$ Graffar class, while the older people without MM are mainly in middle to upper (35.3\%) and upper (17.6\%) Graffar classes.

Conclusions. Multimorbidity is mainly associated with lower social classes. The dependence for DLA appears unrelated to MM. Individuals with multimorbidity need special attention based on socio-economic contexts.

Key words: aged, multimorbidity, activities of daily living, sociological factors, general practice.

Santiago LM, Prazeres F, Boto T, Maurício K, Rosendo I, Simões JA. Multimorbidity daily life activities and socio-economic classification in the Central Portugal primary health care setting: an observational study. Fam Med Prim Care Rev 2020; 22(1): 54-58, doi: https:// doi.org/10.5114/fmpcr.2020.92506.

\section{Background}

Multimorbidity (MM), defined as any combination of a chronic disease with at least one other disease, acute or chronic, and social or individual risk factors [1], is associated with decreased quality of life, mainly due to decreased functional capacity and increased use of health care. Its prevalence is estimated at $72.7 \%$ in adults in Portugal and is thought to increase with age. In older people, this may exceed $95 \%[2,3]$.

$\mathrm{MM}$ is a challenging entity to be managed by the patient, family members, family doctor and society $[4,5]$. The presentation of a variety of chronic diseases in the same patient deserves special attention, because the physician must deal or treat not only one patient with one disease, but one patient with multiple morbidities and expectations or limitations [6].

In Portugal, some studies seem to indicate a relationship between family income, social support and level of dependence on self-care and multimorbidity, but no one has yet studied this issue with a large sample in the field of General Practice/Family Medicine (GP/FM) [7].
The Barthel index $(\mathrm{Bt})$ is an instrument for assessing the degree of independence of the patient to perform ten basic activities of daily living: eating, personal hygiene, use of toilet, bathing, dressing and undressing, urinary sphincter control, faecal sphincter control walking, moving from chair to bed and climbing and descending stairs.

Currently, the Barthel index is considered the most adequate instrument to evaluate the incapacity to perform daily life activities (DLA), which seems to increase with aging [8].

The Graffar index (Gr) allows classification of the socio-economic level of families into four classes: high, medium-high, medium-low and low, based on a set of five criteria: profession, level of schooling, sources of family income, comfort of housing and place of residence [9]. Being classified in a higher socio-economic level is related to greater access to financial and material resources, including health care [10]. There seems to be an association between lower family income and a greater prevalence of MM [11].

To better manage MM, the General Practice/Family Doctor (GP/FD) must have access to information about economic inad- 
equacies, $\mathrm{Gr}$ and to the ability to perform DLAs. DLAs can be measured by two scales: the Katz index and Barthel index, the latter being one that exists in the electronic health records in the Primary Care Health Centres of the Central Region of Portugal.

\section{Objectives}

This study aimed to evaluate the prevalence of $\mathrm{MM}$ and its association with socio-economic classification, by the Graffar index, and the performance of DLA, by the $\mathrm{Br}$ index, in older people, according to the geographic location of residence in Central Portugal, age and gender.

\section{Material and methods}

\section{Study design}

An observational cross-sectional study was carried out in 2019 using informatics data retrieved the 31 ${ }^{\text {st }}$ December 2018.

\section{Setting/participants}

The study population corresponded to all individuals aged 65 to 99 years enrolled in the units of General and Family Medicine, Primary Health Care in the geographical area of the ARS-Centro, namely in the Health Centre Groupings (ACeS) of Baixo Mondego, Baixo Vouga, Cova da Beira, Dão Lafões, Pinhal Interior Norte and Pinhal Litoral, in the two ACeS of the Local Health Unit (ULS) of Castelo Branco (ACeS Beira Interior Sul and ACeS Pinhal Interior Sul) and in the ULS of Guarda.

\section{Variables/data sources}

The study data was collected anonymously from the computerised clinical health records (SClinico) of all individuals regarding age, sex, number of active health problems, ICPC2 codes, Barthel and Graffar indices.

The individuals were divided into three age groups: $65-75$ years, 76-85 years and $86-99$ years.

The Graffar and Barthel indices were collected according to the ordinal classification for both indices and the SClinico constant.
Multimorbidity was defined as having more than two chronic active International Classification for Primary Care (ICPC2) codes.

The study was approved by the Ethics Committee and the Board of the Regional Health Administration of the Centre of Portugal (ARS-Centro).

\section{Measurements}

Data analysis was performed with the SPSS-IBM program, version 24. Descriptive statistics analysis was performed, as well as a non-parametric inferential statistical study, with the Mann-Whitney $\mathrm{U}$ test and Wilcoxon test, as the study variables were ordinal variables, and a value of $p<0.01$ was defined as statistically significant.

\section{Bias}

We anticipated systematic bias of under fill-in of Barthel and Graffar indices and also of ICPC2 classification.

\section{Study size}

This was a study of all the persons attended in Central Portugal National Health Service Primary Health Care Units within the 65 to 99 year age range.

\section{Results}

A population of 190,025 individuals, with a mean age of $80.16 \pm 8.03$ years and a median of 81 years, of which 89,565 (47.1\%) were male, was studied (Table 1 ).

The proportion of patients with known the Barthel index was of $6.3 \%$ in males and $9.0 \%$ in females, $7.4 \%$ in total. The Graffar index was known in $4.9 \%$ of males and $5.5 \%$ of females, $5.2 \%$ in total. The mean number of ICPC2 chronic active problems was $9.1 \pm 2.0$ per person, with a median of 9 , being $8.7 \pm$ 1.8 in men and $9.5 \pm 2.0$ in women $(p<0.001)$.

Table 2 shows the distribution by ACeS, age groups, Barthel and Graffar index full-filled, as well as those suffering from multimorbidity (MM). The ACeS of the interior of the Central Region revealed a higher elderly population, the most numerous age group being $76-85$ years.

\begin{tabular}{|c|c|c|c|c|c|}
\hline & & & \multicolumn{2}{|l|}{ Gender } & \multirow[t]{2}{*}{ Total } \\
\hline & & & Male* & Female* & \\
\hline \multirow[t]{9}{*}{ ACeS } & BM & $n(\%)$ & $7,831(8.7 \%)$ & 8,963 (8.9\%) & $16,794(8.8 \%)$ \\
\hline & BV & $n(\%)$ & 8,514 (9.5\%) & 8,928 (8.9\%) & $17,442(9.2 \%)$ \\
\hline & BIS & $n(\%)$ & $8,926(10 \%)$ & $12,181(12.1 \%)$ & 21,107 (11.1\%) \\
\hline & Cova da Beira & $n(\%)$ & 9,301 (10.4\%) & $13,158(13.1 \%)$ & 22,459 (11.8\%) \\
\hline & Dão Lafões & $n(\%)$ & $9,026(10.1 \%)$ & 7,802 (7.8\%) & $16,828(8.9 \%)$ \\
\hline & ULS Guarda & $n(\%)$ & $17,772(19.8 \%)$ & $14,454(14.4 \%)$ & $32,226(17 \%)$ \\
\hline & PIN & $n(\%)$ & $14,456(16.1 \%)$ & 20,115 (20\%) & $34,571(18.2 \%)$ \\
\hline & PIS & $n(\%)$ & 3,911 (4.4\%) & 5,789 (5.8\%) & $9,700(5.1 \%)$ \\
\hline & $\mathrm{PL}$ & $n(\%)$ & $9,828(11 \%)$ & $9,070(9 \%)$ & $18,898(9.9 \%)$ \\
\hline \multirow[t]{3}{*}{ Age Group } & $65-75$ years & $n(\%)$ & 31,278 (34.9\%) & $28,326(28.2 \%)$ & 59,604 (31.4\%) \\
\hline & $76-85$ years & $n(\%)$ & $39,238(43.8 \%)$ & $35,070(34.9 \%)$ & 74,308 (39.1\%) \\
\hline & $86-99$ years & $n(\%)$ & $19,049(21.3 \%)$ & $37,064(36.9 \%)$ & $56,113(29.5 \%)$ \\
\hline Barthel completed & yes & $n(\%)$ & $5,651(6.3 \%)$ & $9,001(9 \%)$ & $14,652(7.7 \%)$ \\
\hline Graffar completed & yes & $n(\%)$ & 4,432 (4.9\%) & $5,506(5.5 \%)$ & 9,938 (5.2\%) \\
\hline MM & yes & $n(\%)$ & 76,105 (47.8\%) & $83,024(52.2 \%)$ & $159,129(80 \%)$ \\
\hline
\end{tabular}




\begin{tabular}{|c|c|c|c|c|c|}
\hline & & & \multicolumn{2}{|l|}{ MM } & \multirow[b]{2}{*}{ Total } \\
\hline & & & $\begin{array}{l}\text { Yes* } \\
n(\%)\end{array}$ & $\begin{array}{l}\text { No* } \\
n(\%)\end{array}$ & \\
\hline \multirow[t]{9}{*}{ ACeS } & BM & $n(\%)$ & $9,054(5.7 \%)$ & $7,740(25.1 \%)$ & $16,794(8.8 \%)$ \\
\hline & BV & $n(\%)$ & 11,299 (7.1\%) & $6,143(19.9 \%)$ & $17,442(9.2 \%)$ \\
\hline & BIS & $n(\%)$ & $12,181(12.2 \%)$ & $1,749(5.7 \%)$ & 21,107 (11.1\%) \\
\hline & Cova da Beira & $n(\%)$ & $20,831(13.1 \%)$ & $1,628(10.4 \%)$ & 22,459 (11.8\%) \\
\hline & Dão Lafões & $n(\%)$ & $12,219(7.6 \%)$ & 4,699 (15.2\%) & $16,828(8.9 \%)$ \\
\hline & ULS Guarda & $n(\%)$ & 30,371 (19.1\%) & $1,855(6 \%)$ & $32,226(17 \%)$ \\
\hline & PIN & $n(\%)$ & $33,074(20.8 \%)$ & $1,497(4.8 \%)$ & $34,571(18.2 \%)$ \\
\hline & PIS & $n(\%)$ & 8,535 (5.4\%) & $1,165(3.8 \%)$ & $9,700(5.1 \%)$ \\
\hline & $\mathrm{PL}$ & $n(\%)$ & $14,478(9.1 \%)$ & $4,420(14.3 \%)$ & $18,898(9.9 \%)$ \\
\hline \multirow[t]{3}{*}{ Age Group } & $65-75$ years & $n(\%)$ & $44,881(28.2 \%)$ & $8,600(27.8 \%)$ & $53,481(28.1 \%)$ \\
\hline & $76-85$ years & $n(\%)$ & $62,433(39.2 \%)$ & 9,885 (32\%) & $72,318(38.1 \%)$ \\
\hline & $86-99$ years & $n(\%)$ & $51,815(32.6 \%)$ & $12,411(40.2 \%)$ & $64,226(33.8 \%)$ \\
\hline Barthel Completion & yes & $n(\%)$ & $14,445(46.8 \%)$ & $207(0.1 \%)$ & $14,652(7.7 \%)$ \\
\hline Graffar completion & yes & $n(\%)$ & $9,887(5.2 \%)$ & $51(27.1 \%)$ & $9,938(5.2 \%)$ \\
\hline
\end{tabular}

* $p<0.001$, BM - Baixo Mondego, BV - Baixo Vouga, BIS - Beira Interior Sul, PIN - Pinhal Interior Norte, PIS - Pinhal Interior Sul, PL - Pinhal Litoral.

\begin{tabular}{|c|c|c|c|c|c|}
\hline & & & \multicolumn{2}{|l|}{ MM } & \multirow[b]{2}{*}{$\begin{array}{l}\text { Total } \\
n(\%) \\
\end{array}$} \\
\hline & & & $\begin{array}{l}\text { Yes* } \\
n(\%)\end{array}$ & $\begin{array}{l}\text { No* } \\
n(\%) \\
\end{array}$ & \\
\hline \multirow{5}{*}{$\begin{array}{l}\text { Barthel - level of } \\
\text { dependence }\end{array}$} & independent & $n(\%)$ & $7,484(51.8 \%)$ & $88(42.5 \%)$ & 7,572 (51.7\%) \\
\hline & mild & $n(\%)$ & 2,855 (19.8\%) & $34(16.4 \%)$ & 2,889 (19.7\%) \\
\hline & moderate & $n(\%)$ & $1,819(12.6 \%)$ & $28(13.5 \%)$ & $1,847(12.6 \%)$ \\
\hline & severe & $n(\%)$ & 1,393 (9.6\%) & $42(20.3 \%)$ & $1,435(9.8 \%)$ \\
\hline & total dependence & $n(\%)$ & 894 (6.2\%) & $15(7.2 \%)$ & 909 (6.2\%) \\
\hline \multirow{4}{*}{$\begin{array}{l}\text { Graffar - socio-eco- } \\
\text { nomic level }\end{array}$} & lower & $n(\%)$ & 3,146 (31.8\%) & $10(19.6 \%)$ & 3,156 (31.8\%) \\
\hline & middle & $n(\%)$ & $5,466(55.3 \%)$ & $14(27.5 \%)$ & $5,480(55.1 \%)$ \\
\hline & higher middle & $n(\%)$ & 1,171 (11.8\%) & $18(35.3 \%)$ & 1,189 (12\%) \\
\hline & higher & $n(\%)$ & 104 (1.1\%) & 9 (17.6\%) & 113 (1.1\%) \\
\hline
\end{tabular}

$* p<0.001$.

The proportion of MM in this population was found to be $80 \%$, multimorbidity (Table 2 ) being more common in CSAs in the Central Region and in the 76-85 age group. Individuals with MM amounted to $52.2 \%$ female and $85 \%$ of male. For females $82.6 \%$ had MM. We also found that the Barthel and Graffar indices have a significantly more prevalent completion prevalence in people with $\mathrm{MM}$, with an overall completion of $7.7 \%$ and $5.2 \%$.

The distribution of levels of dependence for daily life activities (DLA), as measured by the Barthel index, and socio-economic levels, as measured by the Graffar index, were found to be significantly different between whether an individual had MM (Table 3). It has been verified that, in the elderly with MM and DLA, $51.8 \%$ have independence, $19.8 \%$ have mild dependence, $12.6 \%$ moderate dependence, $9.6 \%$ severe dependence and $6.2 \%$ total dependence. For economy class $31.8 \%$ were in Lower Class, $55.3 \%$ in Middle Class, $11.8 \%$ in Higher Middle Class and $1.1 \%$ in Higher Class.

\section{Discussion}

In this study, data was collected from the electronic health clinic records made by GP/FM physicians concerning the entire elderly population enrolled in primary and general health care units of primary health care in the geographical area of the ARS-
-Centro, Portugal. An $80 \%$ prevalence of multimorbidity (MM) was found, and a low knowledge about socio-economic situation and daily life activities was perceived.

The frequency of MM varies according to the studies due to different methods of data collection, different definitions of $\mathrm{MM}$ and the type of problems studied. The definition of MM which we considered for this study was that which was defined in two studies in Portugal, one defining $\mathrm{MM}$ and the other studying MM prevalence as $80 \%[1,2]$.

One of the limitations of this study is whether all classifications recorded are in line with the accepted MM definition [1]. It is possible that some ICPC2 Classifications are missing and that others should have been removed.

The study population was of 190,025 elderly people. To the authors' knowledge, this is the first study addressing this issue in such a large population.

A population over 65 years of age is most prevalent in ACeS Pinhal Interior Norte (18.2\%), ULS Guarda (17\%), Beira Interior Sul (11.1\%) and Pinhal Interior Sul (5.1\%), which are located in the interior of Portugal away from the seaside, and as we move towards the interior of the Central Region of Portugal, we find more elderly patients. This implies the need for greater attention to the quality and effectiveness of health care, as the elderly population has a greater prevalence of multimorbidity and a greater need for care, [12]. 
In males, the lowest age group prevalence was of those 86-99 years, the oldest ones and in females, the prevalence increased with age meaning that there were more women in the oldest age group.

The rates of Barthel (7.7\%) and Graffar (5.2\%) indices presented very low completion frequencies in the SClinico. These indexes are more often filled-in in females, especially the Barthel Index. One explanation may be that the Barthel index in SClinico is part of the patient's individual clinical process, while the Graffar index is part of the family assessment. Family doctors should be made aware of the importance of completing these scales.

The proportion of $\mathrm{MM}$ in the population over 65 years of age was $80 \%$, which confirms that the consultation of elderly people in General and Family Medicine is the one of MM. The elderly population does not only suffer from one chronic disease, but several, for which there may be several guidelines. These patients have polypharmacotherapy, with carries a risk of adverse effects due to drug interactions. Therefore, it is not only a problem of the management of the diagnosis and expectations about diseases, but also of the management of therapy [13].

Females presents with, on average, one more health problem than males (9.51 vs 8.67 problems) [14]. Despite this, the highest proportion of elderly without MM is female (65.4\%).

MM occurs in a high proportion of elderly people, and the frequency of the group aged between 76 and 85 years, representing $39.1 \%$ of the individuals, is highlighted. This interval includes not only the mean and median ages of this sample, but also the average life expectancy in Portugal of women and men. Therefore, sites with a higher proportion of elderly present higher MMs [15].

Of elderly people without MM, the age group between 86-99 years is the one with the highest population frequency (49.5\%). Thus, the question: do patients without MM live longer $[16,17]$ ?

From Barthel's index it is noticed that there is greater dependence when there is MM [18]. It seems that the use of this scale as a discriminator of future activities with elderly people should be encouraged.

Aging should no longer be seen as a problem of society, and thusly social reintegration of the elderly should be attempted, within reason, in order to increase their participation in ac- tivities that boost their physical and mental capacities, both at home, in day care centres, nursing homes or in Integrated Continued Care $[19,20]$.

After analysing the variation of the MM rate as a function of the Graffar index, it is possible to deduce that there is a greater number of older individuals with $\mathrm{MM}$ at the average socio-economic level (55.3\%), and then at the lower socio-economic level with $31.8 \%$. Worse socio-economic conditions and low social support are a matter for the family doctor to think about when managing the MM patient.

Lower socio-economic levels present higher MM, perhaps due to worse living conditions, risky behaviour or adverse experiences in childhood, and so a therapeutic bewilderment might not be helpful in this MM management. Failure to pay attention to this determinant factor in the health of populations will never achieve the expected results [21].

Higher socio-economic levels, namely the high and higher middle, have the lowest rates of $\mathrm{MM}, 11.8 \%$ and $1.1 \%$, respectively. Therefore, it can also be inferred that the life conditions may be influence the amount of diseases, hence MM [22].

The patient must be inserted in its social context so that the family physician can know how best to help him to control his MM. And before the onset of the chronic disease, one must work on its prevention [23, 24].

Future works must correlate Lawton and Brody scale [25] with Prism 7 [26] and Katz scales [27]

These results imply, consequently, that doctors in GP/FM need to be more aware of this issue. No other study, with this or any other methodology, has been published in Portugal.

\section{Conclusions}

1. This study evidenced high frequencies of multimorbidity, especially in the interior of the centre of Portugal and in the people between 76 and 85 years of age.

2. Multimorbidity in the elderly is associated with lower social classes.

3. Dependence for daily life activities appears unrelated to multimorbidity.

4. Individuals with multimorbidity need special attention, based on socio-economic contexts.

5. More attention is needed for Barthel and Graffar indexes filling-in by doctors.

Source of funding: This work was funded from the authors' own resources.

Conflicts of interest: The authors declare no conflicts of interest.

\section{References}

1. Prazeres F, Santiago LM, Simões JA. Defining multimorbidity. From English to Portuguese Using a Delphi Technique. BioMed Research International 2015, doi: 10.1155/2015/965025.

2. Prazeres F, Santiago LM. Prevalence of Multimorbidity in the adult population attending primary care in Portugal: a cross-sectional study. BMJ Open 2015; 5(9), doi: 10.1136/bmjopen-2015-009287.

3. Violan C, Foguet-Boreu Q, Flores-Mateo G, el al. Prevalence, determinants and patterns of Multimorbidity in primary care: a systematic review of observational studies. PLOS ONE 2014; 9(7): e102149, doi: 10.1371/journal.pone.0102149.

4. Smith SM, Soubhi $\mathrm{H}$, Fortin M, et al. Managing patients with Multimorbidity: systematic review of interventions in primary care and community. BMJ 2012; 345: e5205, doi: 10.1136/bmj.e5205.

5. Haslam D. "You' re an expert in me": the role of the generalist doctor in the management of patients with Multimorbidity. J Comorb 2015; 5: 132-134, doi: 10.15256/joc.2015.5.65

6. Sinnott C, McHugh S, Browne J, et al. GPs' perspectives on the management of patients with Multimorbidity: systematic review and synthesis of qualitative research. BMJ Open 2013; 3(9): e003610, doi: 10.1136/bmjopen-2013-003610.

7. Prazeres F, Santiago LM. Relationship between health-related quality of life, perceived family support and unmet health needs in adult patients with Multimorbidity attending primary care in Portugal: a multicentre cross-sectional study. Health Qual Life Outcomes 2016; 14(1): 1-11, doi: 10.1186/s12955-016-0559-7.

8. Araújo F, Ribeiro J, Oliveira A, et al. [Validation of the Barthel Index in a sample of non-institutionalized elderly]. Rev Port Saude Publica 2007; 25(2): 59-66 (in Portuguese).

9. Amaro F. [Adapted Graffar Scale]. In: Costa A, Leitão F, Santos J, eds. [Functional Resumes] Vol. II. Lisboa: IIE; 1996 (in Portuguese).

10. Assari S, Lankarani MM. Does multi-morbidity mediate the effect of socioeconomics on self-rated health? Cross-country differences. Int J Prev Med 2015; 6: 85, doi: 10.4103/2008-7802.164413. 
11. Wendt A, Tomasi E, Cesar JA, et al. Inequalities in Multimorbidity among elderly: a population-based study in a city in Southern Brazil. Cad Saude Publica 2018; 34(11): e00040718, doi: 10.1590/0102-311X00040718.

12. Teixeira V, Macedo A, Borges C, et al. [Socioeconomic status and access to Primary Health Care: a cross-sectional study in four health units in Northern Portugal]. Rev Port Med Geral Fam 2016; 32: 376-386, doi: 10.32385/rpmgf.v32i6.11958 (in Portuguese).

13. Wallace E, Salisbury C, Guthrie B, et al. Managing patients with Multimorbidity in primary care. BMJ 2015; 350: h176, doi: 10.1136/ bmj.h176.

14. Romana GQ, Kislaya I, Salvador MR, et al. [Multimorbidity in Portugal: results from the first national health examination survey]. Acta Med Port 2019; 32(1): 30-37, doi: 10.20344/amp.11227 (in Portuguese).

15. Rodrigues AM, Gregório MJ, Sousa RD, et al. [Challenges of ageing in Portugal: data from the EpiDoC cohort]. Acta Med Port 2018; 31(2): 80-93, doi: 10.20344/amp.9817 (in Portuguese).

16. Nunes BP, Flores TR, Mielke GI, et al. Multimorbidity and mortality in older adults: a systematic review and meta-analysis. Arch Gerontol Geriatr 2016; 67: 130-138, doi: 10.1016/j.archger.2016.07.008.

17. Olaya B, Domènech-Abella J, Moneta MV, et al. All-cause mortality and Multimorbidity in older adults: the role of social support and Ioneliness. Exp Gerontol 2017; 99: 120-126, doi: 10.1016/j.exger.2017.10.001.

18. Bleijenberg N, Zuithoff NPA, Smith AK, et al. Disability in the individual ADL, IADL, and Mobility among Older Adults: a prospective cohort study. J Nutr Health Aging 2017; 21(8): 897-903, doi: 10.1007/s12603-017-0891-6.

19. Fenton JJ, Levine MD, Mahoney LD, et al. Bringing geriatricians to the front lines: evaluation of a quality improvement intervention in Primary Care. J Am Board Fam Med 2006; 19(4): 331-339.

20. Simões JA. [Bioethical reflections about the situation of the elderly and their families]. Acta Med Port 2010; 23(3): $483-492$ (in Portuguese).

21. Hoffman R, Kröger H, Pakpahan E. Pathways between socioeconomic status and health: does health selection or social causation dominate in Europe? Adv Life Course Res 2018; 36(2018): 23-36, doi: 10.1016/j.alcr.2018.02.002.

22. Schäfer I, Hansen H, Schön G, et al. The influence of age, gender and socio-economic status on Multimorbidity patterns in primary care. First results from the multicare cohort study. BMC Health Serv Res 2012; 12(1): 89, doi: 10.1186/1472-6963-12-89.

23. Milani RV, Lavie CJ. Health Care 2020: Reengineering health care delivery to combat chronic disease. Am J Med 2016; 128(4): 337-343, doi: 10.1016/j.amjmed.2014.10.047.

24. Portuguese Republic. Interministerial working group. [National strategy for active and healthy aging 2017-2025] [cited 15.03.2019]. Available from URL: https://www.sns.gov.pt/wp-content/uploads/2017/07/ENEAS.pdf. (in Portuguese).

25. Portuguese Society of Internal Medicine. GERMI - Nucleus of Geriatrics Studies. [Geriatric Evaluation] [cited 20.02.2019]. Available from URL: https://www.spmi.pt/docs_nucleos/GERMI_36.pdf. (in Portuguese).

26. Saenger ALF, Caldas CP, Raîche $M$, et al. Identifying the loss of functional independence of older people residing in the community: validation of the PRISMA-7 instrument in Brazil. Arch Gerontol Geriatr 2018; 74: 62-67, doi: 10.1016/j.archger.2017.09.008.

27. Duarte YAO, Andrade CL, Lebrão ML. [Katz Index on elderly functionality evaluation]. Rev Esc Enferm USP. 2007; 42(2): 317-325, doi: 10.1590/S0080-62342007000200021 (in Portuguese).

Tables: 3

Figures: 0

References: 27

Received: 29.04.2019

Reviewed: 20.05 .2019

Accepted: 25.09.2019

Address for correspondence:

Luiz Miguel Santiago, MD, PhD, Assoc. Prof.

Faculdade de Medicina da Universidade de Coimbra

Azinhaga de Santa Comba (Celas)

3000-548 Coimbra

Portugal

Tel.: +351966225773

E-mail: luizmiguel.santiago@gmail.com 